Org Lett. 2017 June 02; 19(11): 2837-2840. doi:10.1021/acs.orglett.7b01009.

\title{
Improved Synthesis for Modular Ascarosides Uncovers Biological Activity
}

\author{
Ying K Zhang ${ }^{\dagger}$, Marco A Sanchez-Ayala ${ }^{\dagger}$, Paul W. Sternberg ${ }^{\ddagger}$, Jagan Srinivasan $§$, and Frank \\ C. Schroeder ${ }^{\dagger}$ \\ †Boyce Thompson Institute and Department of Chemistry and Chemical Biology, Cornell \\ University, Ithaca, New York 14853, United States \\ ҒHoward Hughes Medical Institute and Division of Biology, California Institute of Technology, \\ Pasadena, California 91125, United States \\ $\S$ Department of Biology and Biotechnology, Worcester Polytechnic Institute, Worcester, \\ Massachusetts 01609, United States
}

\begin{abstract}
A versatile synthesis of modular ascarosides, a family of signaling molecules from Caenorhabditis elegans and other nematodes, via hydrogenolysis of a cyclic sulfate derived from methyl- $a$-Lrhamnopyranoside is reported. The route enables selective introduction of different side chains at the 1,2, and 4 positions of the sugar, as demonstrated for ascarosides from C. elegans and Pristionchus pacificus. Bioassays with synthetic samples of $4^{\prime}$-tigloyl ascaroside mbas \#3 revealed its role as an avoidance or dispersal signal.
\end{abstract}

\section{Graphical abstract}

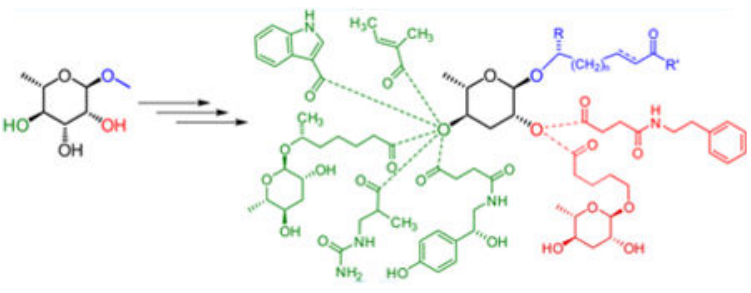

Over the past decade, a group of specialized metabolites, the nematode-derived modular metabolites (NDMMs), have been identified from the model organism C. elegans and other nematodes. ${ }^{1,2}$ These compounds are derived from glycosides of the dideoxy sugars Lascarylose and L-paratose, which are decorated with diverse building blocks from amino acid, nucleoside, carbohydrate, and fatty acid metabolism (Figure 1). ${ }^{1,3}$ NDMMs function as signaling molecules that regulate many aspects of nematode life history, including

Correspondence to: Frank C. Schroeder.

ORCID: Frank C. Schroeder: 0000-0002-4420-0237

Supporting Information: The Supporting Information is available free of charge on the ACS Publications website at DOI: 10.1021/ acs.or-glett.7b01009.

Notes: The authors declare no competing financial interest. 
development, ${ }^{4-7}$ lifespan, ${ }^{8,9}$ morphology, ${ }^{10}$ social communication, ${ }^{6,7,11-15}$ as well as interactions with other species. ${ }^{16-18}$ Since even small changes in the chemical structures of NDMMs can greatly affect biological activity and NDMMs can be active at extremely low (femtomolar) concentrations, ${ }^{12,19}$ requirements for the purity of synthetic samples for bioassays are particularly stringent. Previous syntheses of ascaroside- and paratoside-based NDMMs employed 2,4-di- $O$-benzoylascarylose 2 as a key intermediate, which was obtained in six steps from 1 (Figure 2). ${ }^{4,20-22}$ An improved version of this route was reported by Knolker et al. ${ }^{23}$ However, 2 does not permit regioselective modification or introduction of other substituents at the $2^{\prime}$ - and $4^{\prime}$-positions and, thus, is illsuited for the selective synthesis of $2^{\prime}$ - or $4^{\prime}$-substituted NDMMs.

We aimed to develop a synthesis for a key intermediate that would enable straightforward differentiation of the $2^{\prime}$ and $4^{\prime}$ positions. Recognizing that the crucial $3^{\prime}$ deoxygenation would be facilitated by using an activating group that could double as a protecting group for the $2^{\prime}$ hydroxy group, we turned our attention to Klemer-Rodemeyer-like transformations. Based on literature precedent, ${ }^{24,25}$ inverse Klemer-Rodemeyer fragmentation of 2,3-Obenzylidinerhamnose derivative 3 was expected to furnish ascarylose derivative 5 but instead produced the dihydropyran $\mathbf{4}$ as the major product, likely as a result of abstraction of the benzylic proton (Scheme 1). Inspired by the work of van Boom and co-workers, ${ }^{26}$ we then considered a strategy based on regioselective opening of cyclic sulfates, whose utility is being increasingly recognized in carbohydrate chemistry. ${ }^{27}$ Commercially available methyl L-rhamnopyrano-side 6 was treated with 2,2-dimethoxypropane to afford 7, followed by TBDPS protection. In the presence of excess TBDPSCl, acetonide deprotection occurred during silica gel chromatography to directly afford diol 8 in nearly quantitative yield. Treatment of $\mathbf{8}$ with thionyl chloride led to cyclic sulfite $\mathbf{9}$, which was subsequently oxidized with sodium periodate in the presence of a catalytic amount of ruthenium trichloride to give cyclic sulfate 10. In addition, the corresponding 4-methoxybenzyl-protected derivative 14 was prepared as described by van Boom and co-workers. ${ }^{26}$ Reduction of $\mathbf{1 4}$ with tetrabutylammonium borohydride produced the two regioisomers $\mathbf{1 5}$ and $\mathbf{1 6}$ in a ratio of about 6:1, as reported. ${ }^{26}$ Better regioselectivity (15:1, easily separable) was achieved when the corresponding $4^{\prime}$-TBDPS-protected derivative 10 was used.

Next, we explored the effect of different protective groups in position $2^{\prime}$ on the outcome of subsequent glycosylation reactions. Although the use of the $2^{\prime}$-benzyl derivative would offer advantages for the synthesis of some modular ascarosides, we expected $2^{\prime}$-benzoyl protection to be preferable, as anchimeric assistance of the benzoyl carbonyl would provide better stereoselectivity of the glycosylation step. In test reactions with (2R)-5-hexen-2-ol, we found that the $2^{\prime}$-benzyl derivative produced acceptable yields of the desired $a$-anomer (ratio $a: \beta=7: 1$ ); however, we ultimately proceeded using the $2^{\prime}$-benzoyl derivative 13 because of better yields in subsequent steps, in addition to better stereoselectivity of the glycosylation (ratio $a: \beta>50: 1$ ).

To demonstrate the synthetic utility of 13, we selected three modular ascarosides: icas\#9 and mbas\#3 from $C$. elegans and dasc\#1 from $P$. pacificus. The dimeric ascaroside dasc\#1 has recently been shown to regulate mouth form development in $P$. pacificus, ${ }^{10}$ and synthetic dasc\#1 is urgently needed for the study of the underlying signaling pathways, which are of 
great interest for understanding development of morphology in animals. ${ }^{28,29}$ The indole ascaroside icas\#9 is one of the most abundant indole ascarosides, acts as a strong hermaphrodite attractant in C. elegans, and contributes to induction of larval diapause (dauer). ${ }^{12,30}$ In contrast, nothing is known about the biological activity of mbas $\# 3,{ }^{19}$ in part because previous syntheses yielded insufficient material for bioassays.

Starting from benzoyl derivative 13, icas\#9 was synthesized in nine steps with an overall yield of $15 \%$ (Scheme 2). After removal of the anomeric methyl using $\mathrm{BBr}_{3}$ and glycosylation of (2R)-5-hexen-2-ol, the terminal double bond was oxidized to the corresponding carboxylic acid 24. Following debenzoylation and dibenzylation, the TBDPS group was removed to yield intermediate 27. Finally, attachment of the indole carboxy moiety and subsequent debenzylation afforded icas\#9. Using an analogous sequence, dasc\#1 was synthesized from key intermediate $\mathbf{1 3}$ in eight steps with an overall yield of $7 \%$ (Scheme 2). For the synthesis of mbas\#3, we had to take into account that the presence of the tigloyl and unsaturated side chain preclude a hydrogenation step. Therefore, we here employed 4-methoxybenzyl for $2^{\prime}$-protection, which could be easily removed using trifluoroacetic acid. In this way, mbas\#3 was synthesized from key intermediate $\mathbf{1 3}$ in eight steps with an overall yield of $22 \%$ (Scheme 2).

Next, we explored the biological properties of mbas\#3 in bioassays with C. elegans. Since it is structurally related to icas\#3 (Figure 1), differing only in the nature of the $\mathbf{4}^{\prime}$-substituent, we tested mbas\#3 in an assay that had previously been used to characterize icas\#3 as an attractive pheromone (Figure 3). ${ }^{12}$ Strikingly, we found that, in contrast to icas\#3, which was tested in parallel, mbas\#3 is not attractive and instead triggers avoidance behavior. Avoidance behavior was observed in assays with the common laboratory strain N2 Bristol as well as in CB4856, a C. elegans strain originally collected in Hawaii that differs from the laboratory strain $\mathrm{N} 2$ in that it has a higher propensity to aggregate on food. ${ }^{31} \mathrm{In}$ order to exclude the possibility that the observed behavioral effects of mbas\#3 are due to synergy with other ascarosides produced by the worms during the assays, we also tested the effect of mbas\#3 on daf-22 mutant worms that do not produce any ascaroside-based signaling molecules because of a defect in peroxisomal $\beta$-oxidation. ${ }^{19}$ Similar to the results we obtained for N2 Bristol and CB4856, mbas\#3 triggered avoidance behavior in daf-22 mutant worms.

These results suggest that mbas\#3 serves as a dispersal signal in $C$. elegans that may antagonize the attractive properties of indole ascarosides such as icas\#3 and icas\#9 in a manner similar to the antagonistic effects of high concentrations of ascr\#3 on icas\#3mediated attraction. ${ }^{12}$ Avoidance behavior induced by mbas\#3 also differs from previously described avoidance behavior triggered by another ascaroside, osas\#9. osas\#9, an ascaroside specifically produced in large quantities by starved L1 larvae, triggers avoidance behavior only in starved worms, but not in worms that have access to food, ${ }^{11}$ whereas mbas\#3, which is produced by $\mathrm{C}$. elegans larvae and adults, triggers avoidance even in the presence of food.

In summary, we report a synthetic strategy that enables selective preparation of $2^{\prime}$ - or $4^{\prime}$ substituted ascarosides, based on reductive opening of a rhamnose-derived cyclic sulfate. The new approach enabled facile access to synthetic samples of very high purity of three 
modular ascarosides, icas\#3, dasc\#1, and mbas\#3. Testing of synthetic mbas\#3 revealed that this ascaroside mediates a novel, unexpected behavioral phenotype. Availability of synthetic mbas\#3 and other ascarosides of high purity will enable further, more detailed studies of their biological roles.

\section{Supplementary Material}

Refer to Web version on PubMed Central for supplementary material.

\section{Acknowledgments}

This work was supported in part by the NIH (GM113692 and GM088290 to FCS) and the Howard Hughes Medical Institute. We thank Robert J. Micikas (University of Pennsylvania) for helpful comments and Alexander Artyukhin (Boyce Thompson Institute) for assistance with mass spectrometry.

\section{References}

1. von Reuss SH, Schroeder FC. Nat Prod Rep. 2015; 32:994-1006. [PubMed: 26059053]

2. Schroeder FC. Chem Biol. 2015; 22:7-16. [PubMed: 25484238]

3. Panda O, Akagi AE, Artyukhin AB, Judkins JC, Le HH, Mahanti P, Cohen SM, Sternberg PW, Schroeder FC. Angew Chem, Int Ed. 2017; 56:4729-4733.

4. Jeong PY, Jung M, Yim YH, Kim H, Park M, Hong E, Lee W, Kim YH, Kim K, Paik YK. Nature. 2005; 433:541-545. [PubMed: 15690045]

5. Butcher RA, Fujita M, Schroeder FC, Clardy J. Nat Chem Biol. 2007; 3:420-422. [PubMed: 17558398]

6. Pungaliya C, Srinivasan J, Fox BW, Malik RU, Ludewig AH, Sternberg PW, Schroeder FC. Proc Natl Acad Sci U S A. 2009; 106:7708-7713. [PubMed: 19346493]

7. Srinivasan J, Kaplan F, Ajredini R, Zachariah C, Alborn HT, Teal PEA, Malik RU, Edison AS, Sternberg PW, Schroeder FC. Nature. 2008; 454:1115-1118. [PubMed: 18650807]

8. Ludewig AH, Izrayelit Y, Park D, Malik RU, Zimmermann A, Mahanti P, Fox BW, Bethke A, Doering F, Riddle DL, Schroeder FC. Proc Natl Acad Sci U S A. 2013; 110:5522-5527. [PubMed: 23509272]

9. Aprison EZ, Ruvinsky I. Curr Biol. 2016; 26:2827-2833. [PubMed: 27618262]

10. Bose N, Ogawa A, von Reuss SH, Yim JJ, Ragsdale EJ, Sommer RJ, Schroeder FC. Angew Chem, Int Ed. 2012; 51:12438-12443.

11. Artyukhin AB, Yim JJ, Srinivasan J, Izrayelit Y, Bose N, von Reuss SH, Jo Y, Jordan JM, Baugh LR, Cheong M, Sternberg PW, Avery L, Schroeder FC. J Biol Chem. 2013; 288:18778-18783. [PubMed: 23689506]

12. Srinivasan J, von Reuss SH, Bose N, Zaslaver A, Mahanti P, Ho MC, O'Doherty OG, Edison AS, Sternberg PW, Schroeder FC. PLoS Biol. 2012; 10:e1001237. [PubMed: 22253572]

13. Izrayelit Y, Srinivasan J, Campbell SL, Jo Y, von Reuss SH, Genoff MC, Sternberg PW, Schroeder FC. ACS Chem Biol. 2012; 7:1321-1325. [PubMed: 22662967]

14. Kaplan F, Srinivasan J, Mahanti P, Ajredini R, Durak O, Nimalendran R, Sternberg PW, Teal PE, Schroeder FC, Edison AS, Alborn HT. PLoS One. 2011; 6:e17804. [PubMed: 21423575]

15. Dong C, Dolke F, von Reuss SH. Org Biomol Chem. 2016; 14:7217-7225. [PubMed: 27381649]

16. Manosalva P, Manohar M, von Reuss SH, Chen S, Koch A, Kaplan F, Choe A, Micikas RJ, Wang X, Kogel KH, Sternberg PW, Williamson VM, Schroeder FC, Klessig DF. Nat Commun. 2015; 6:7795. [PubMed: 26203561]

17. Hsueh YP, Mahanti P, Schroeder FC, Sternberg PW. Curr Biol. 2013; 23:83-86. [PubMed: 23246407]

18. Zhao L, Zhang X, Wei Y, Zhou J, Zhang W, Qin P, Chinta S, Kong X, Liu Y, Yu H, Hu S, Zou Z, Butcher RA, Sun J. Nat Commun. 2016; 7:12341. [PubMed: 27477780] 
19. von Reuss SH, Bose N, Srinivasan J, Yim JJ, Judkins JC, Sternberg PW, Schroeder FC. Comparative metabolomics reveals biogenesis of ascarosides, a modular library of small molecule signals in C. elegans. J Am Chem Soc. 2012; 134:1817-1824. [PubMed: 22239548]

20. Varela OJ, Cirelli AF, De Lenderkremer RM. $\beta$-Elimination in aldonolactones. Carbohydr Res. 1979; 70:27-35.

21. Hollister KA, Conner ES, Zhang X, Spell M, Bernard GM, Patel P, de Carvalho AC, Butcher RA, Ragains JR. Ascaroside activity in Caenorhabditis elegans is highly dependent on chemical structure. Bioorg Med Chem. 2013; 21:5754-5769. [PubMed: 23920482]

22. Jung M, Lee Y, Moon HI, Jung Y, Jung H, Oh M. Total synthesis and anticancer activity of highly potent novel glycolipid derivatives. Eur J Med Chem. 2009; 44:3120-3129. [PubMed: 19342127]

23. Martin R, Schafer T, Theumer G, Entchev EV, Kurzchalia TV, Knolker HJ. Synthesis. 2009; 2009:3488-3492.

24. Morin C. Chem Lett. 1986; 15:1055-1056.

25. Klemer A, Rodemeyer G. Chem Ber. 1974; 107:2612-2614.

26. Zegelaar-Jaarsveld K, van der Plas SC, van der Marel GA, van Boom JH. J Carbohydr Chem. 1996; 15:665-689.

27. Megia-Fernandez A, Morales-Sanfrutos J, Hernandez-Mateo F, Santoyo-Gonzalez F. Curr Org Chem. 2011; 15:401-432.

28. Serobyan V, Xiao H, Namdeo S, Rodelsperger C, Sieriebriennikov B, Witte H, Roseler W, Sommer RJ. Nat Commun. 2016; 7:12337. [PubMed: 27487725]

29. Ragsdale EJ, Muller MR, Rodelsperger C, Sommer R. JCell. 2013; 155:922-933.

30. Greene JS, Brown M, Dobosiewicz M, Ishida IG, Macosko EZ, Zhang X, Butcher RA, Cline DJ, McGrath PT, Bargmann CI. Nature. 2016; 539:254-258. [PubMed: 27799655]

31. de Bono M, Bargmann CI. Cell. 1998; 94:679-689. [PubMed: 9741632] 

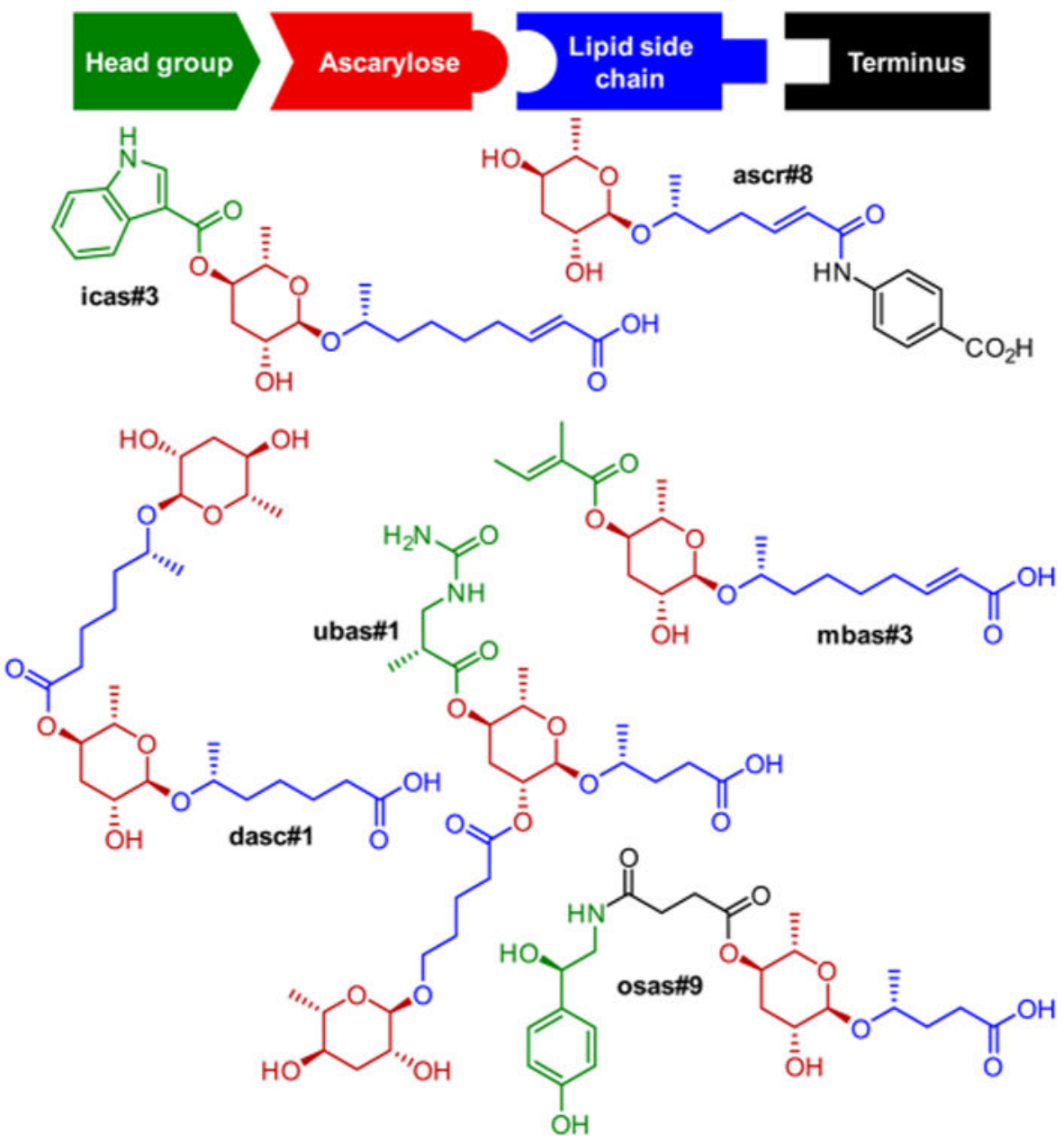

Figure 1.

Modular ascarosides incorporating building blocks from neurotransmitter (osas\#9), folate (ascr\#8), tryptophan (icas\#3), and short-chain fatty acid (mbas\#3) metabolism from $C$. elegans and, from the satellite model organism $P$. pacificus, dimeric ascarosides ubas\#1 and dasc\#1. 

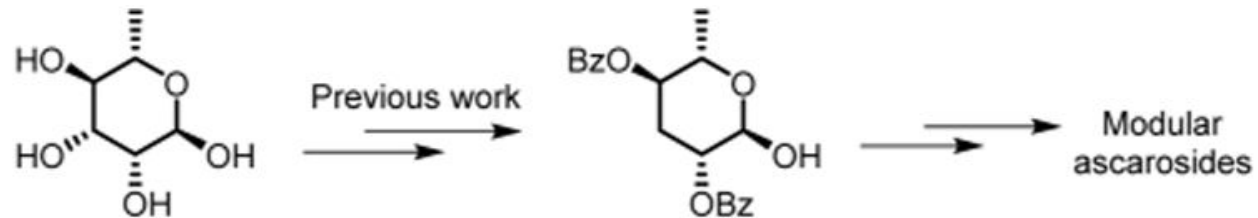

1, L-Rhamnose

2, 2,4-Di-O-benzoylascarylose

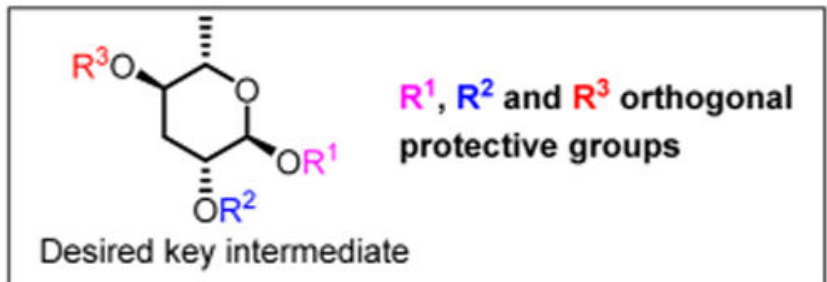

Figure 2.

Previous approach to ascaroside synthesis and the desired key intermediate. 


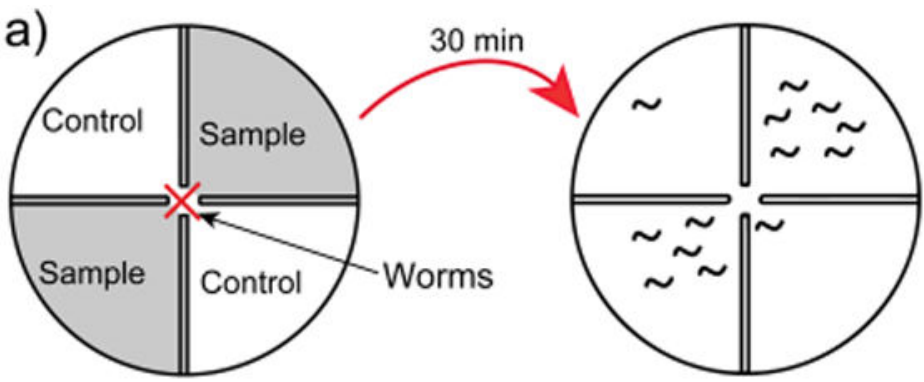

b)

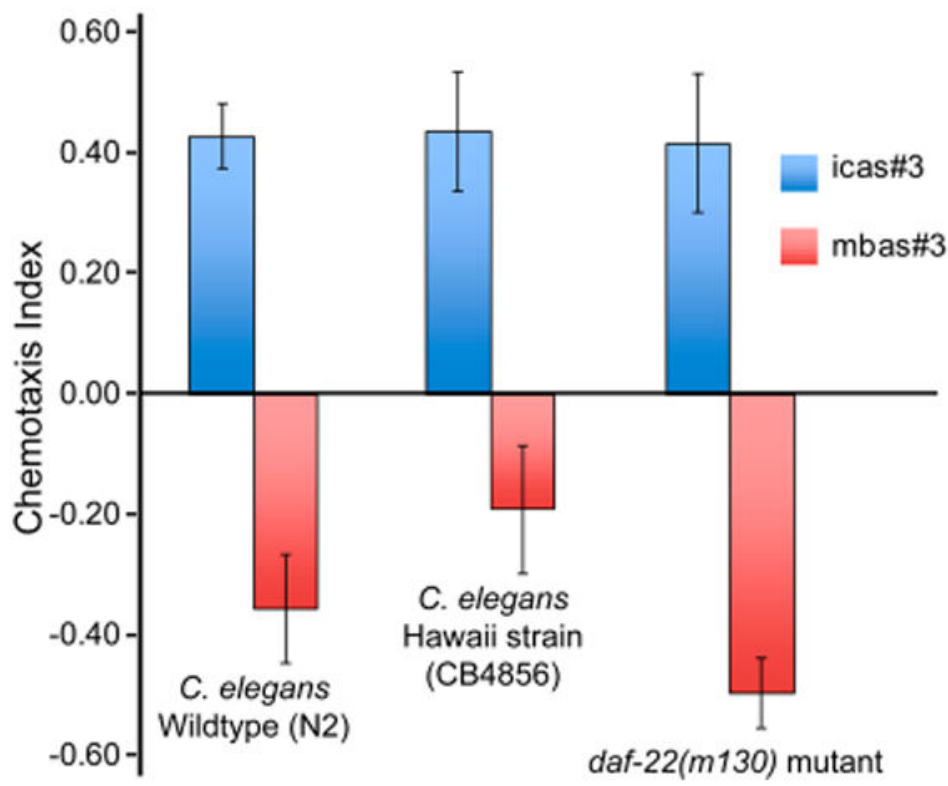

Figure 3.

Quadrant assay used to measure attractive and repulsive properties of icas\#3 and mbas\#3. (a) Agar plates were divided into quadrants, with opposite quadrants containing icas\#3 at $1 \mathrm{pM}$ or mbas\#3 at $10 \mathrm{nM}$. Worms were placed into the center of the plate and their location tracked over time. (b) Chemotaxis indices measured for icas\#3 and mbas\#3. See Srinivasan et al. ${ }^{12}$ for methods. 
a)

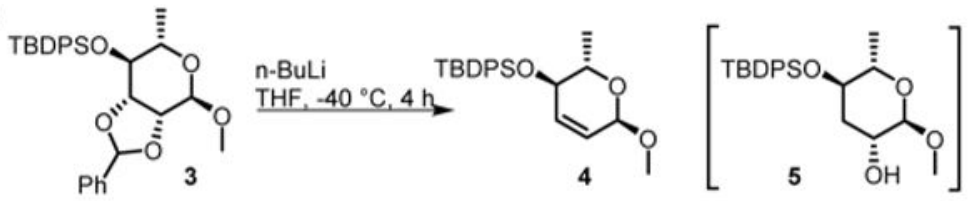

b)
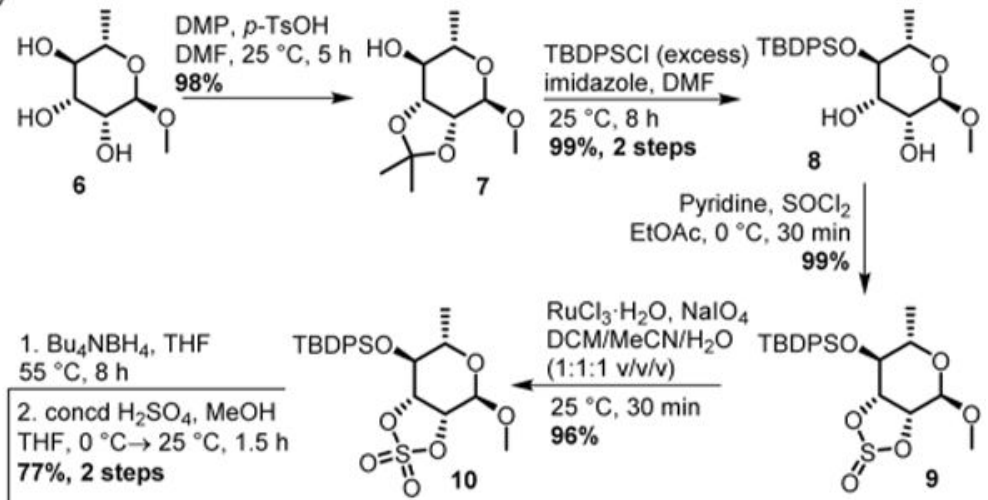

$\checkmark$

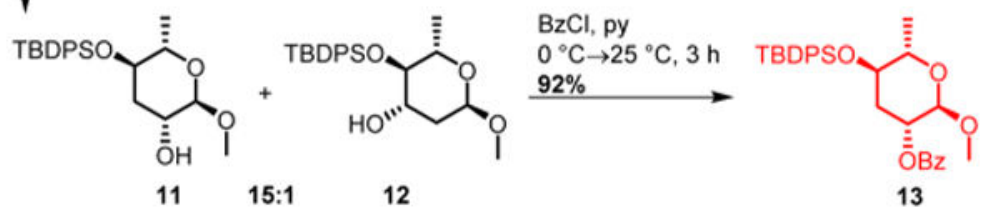

c)

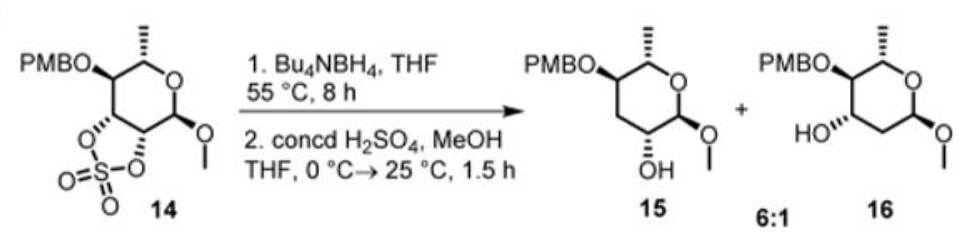

Scheme 1.

Inverse Klemer-Rodemeyer Fragmentation of 2,3- $O$-Benzylidinerhamnose Derivative 8 (a) and Preparation of Ascaroside Derivatives via Methoxyrhamnose-Derived Cyclic Sulfates $(\mathrm{b}, \mathrm{c})$ 

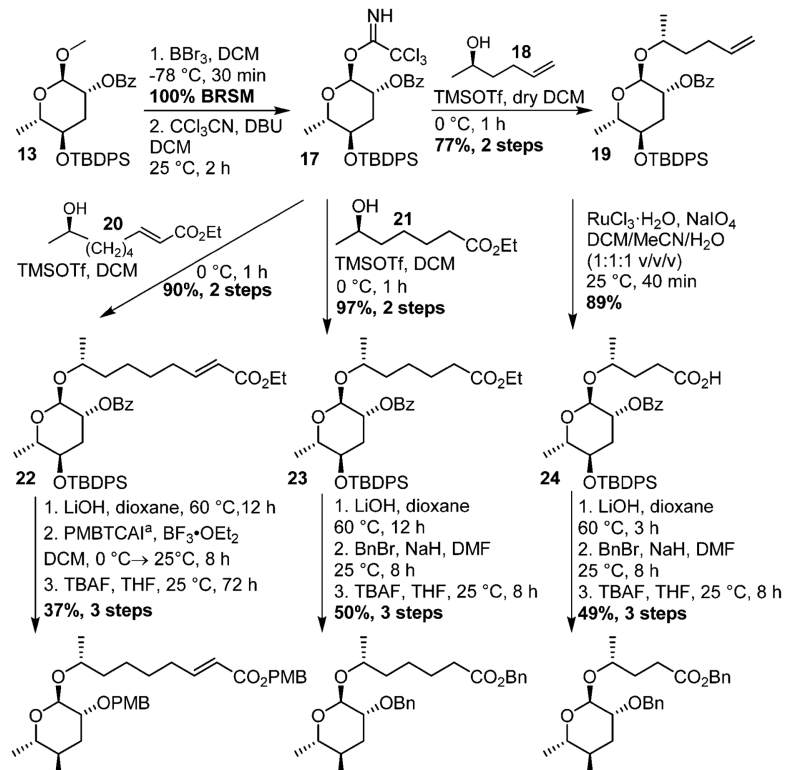

$25 \mathrm{OH}$

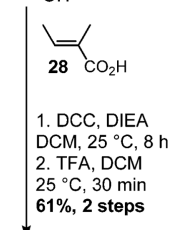

$26 \mathrm{OH}$

$27 \mathrm{OH}$
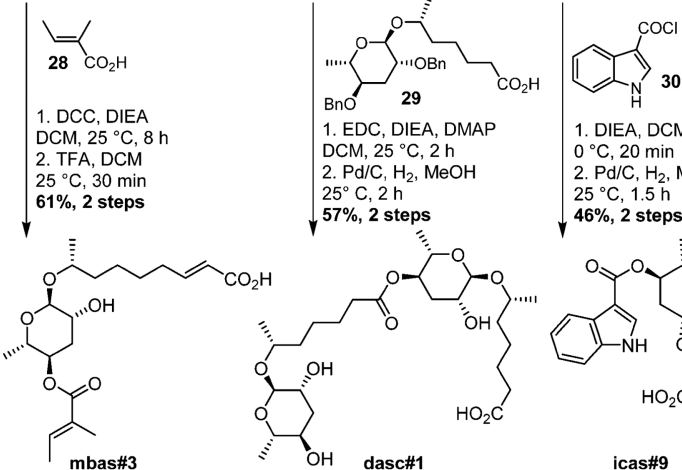

1. EDC, DIEA, DMAP 1 DIEA, DCM

DCM, $25^{\circ} \mathrm{C}, 2 \mathrm{~h} \quad 0^{\circ} \mathrm{C}, 20 \mathrm{~min}$

2. $\mathrm{Pd} / \mathrm{C}, \mathrm{H}_{2}, \mathrm{MeOH} \quad$ 2. $\mathrm{Pd} / \mathrm{C}, \mathrm{H}_{2}, \mathrm{MeOH}$

$25^{\circ} \mathrm{C}, 2 \mathrm{~h}$

$46 \%, 2$ steps

Scheme 2.

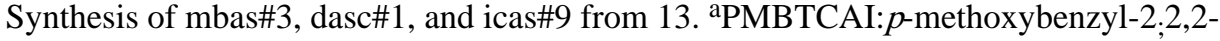
trichloroacetimidate

Org Lett. Author manuscript; available in PMC 2018 June 02. 